\title{
Assessment and Certification of Higher Education for Sustainable Development
}

Citation for published version (APA):

Roorda, N., \& Martens, P. (2008). Assessment and Certification of Higher Education for Sustainable Development. Sustainability: The journal of Record, 1(1), 41-56. https://doi.org/10.1089/SUS.2008.9990

Document status and date:

Published: 01/01/2008

DOI:

10.1089/SUS.2008.9990

Document Version:

Publisher's PDF, also known as Version of record

Document license:

Taverne

Please check the document version of this publication:

- A submitted manuscript is the version of the article upon submission and before peer-review. There can be important differences between the submitted version and the official published version of record.

People interested in the research are advised to contact the author for the final version of the publication, or visit the DOI to the publisher's website.

- The final author version and the galley proof are versions of the publication after peer review.

- The final published version features the final layout of the paper including the volume, issue and page numbers.

Link to publication

\footnotetext{
General rights rights.

- You may freely distribute the URL identifying the publication in the public portal. please follow below link for the End User Agreement:

www.umlib.nl/taverne-license

Take down policy

If you believe that this document breaches copyright please contact us at:

repository@maastrichtuniversity.nl

providing details and we will investigate your claim.
}

Copyright and moral rights for the publications made accessible in the public portal are retained by the authors and/or other copyright owners and it is a condition of accessing publications that users recognise and abide by the legal requirements associated with these

- Users may download and print one copy of any publication from the public portal for the purpose of private study or research.

- You may not further distribute the material or use it for any profit-making activity or commercial gain

If the publication is distributed under the terms of Article $25 \mathrm{fa}$ of the Dutch Copyright Act, indicated by the "Taverne" license above, 


\section{Assessment and Certification of Higher Education for Sustainable Development}

\section{By Niko Roorda ${ }^{1}$ and Pim Martens ${ }^{2}$}

\section{Abstract}

This article describes the characteristics and results of an instrument used for the assessment of the integration of sustainable development in institutions of higher education. Reasons for the application of such an instrument are given, followed by an overview of the requirements that can be set for such an instrument in order to be effective. The particular instrument described is called AISHE (assessment instrument for sustainability in higher education), which has been developed by the Dutch organization for the advancement of sustainable development in higher education (DHO). The development and validation process is described. The relation with the quality management in higher education is explained, including the certification system and the consequences for the accreditation of universities. An overview is given of the practical experiences (case studies) with AISHE in the last five years. Lastly, the most recent developments in higher education are described, and the consequences for the assessment process are discussed. A new project is introduced for the development of an updated version of the instrument called AISHE 2.0.

Keywords: AISHE, assessment, certifcation, DHO, ESD, higher education, policy development, quality management, sustainable development

\section{Fundamentals}

\section{Definitions}

THIS REPORT IS ABOUT ASSESSMENT INSTRUMENTS (AI) used for education for sustainable development (ESD). Although such instruments will no doubt

' DHO (Stichting Duurzaam Hoger OnderwijsDutch Foundation for Sustainable Higher Education), Avans Hogeschool (Avans University for Professional Education), Netherlands.

${ }^{2}$ International Centre for Integrated assessment and Sustainable development,

Maastricht University, Maastricht, Netherlands. be relevant to all levels of formal education, as well as for informal education (such as lifelong learning), this paper is limited in scope to formal higher education (HE), organized by higher education institutions (HEI). These HEIs include universities as well as hogescholen (the Netherlands), Fachhochschule (Germany, Austria, and Switzerland), högskola (Sweden), CVUs (Denmark), institutes of technology (Ireland), and ammattikorkeakoulu (Finland), usually described in English as universities for "professional/vocational education" or for "applied science."

One such assessment instrument is AISHE (assessment instrument for sustainability in higher education), developed in 2000-2001 by the Dutch ESD organization DHO (Dutch organization for the advancement of sustainable development in higher education).

There are several reasons why an AI for ESD is important to realizing the goals of the United Nations Decade of Education for Sustainable Development (DESD) (Table 1).

\section{Table 1. Nine Reasons for the Assessment of ESD}

1. Assessment $=$ tool for policy development

2. Assessment $=$ tool for evaluation of policy needs

3. Assessment strengthens awareness and support for ESD among management, staff, and students

4. Integration of ESD in quality management is necessary to get ESD in mainstream of $\mathrm{HE}$

5. Reporting offers transparency toward stakeholders (financiers, potential students, etc.)

6. Reporting strengthens feeling of responsibility among management and staff

7. ESD certification works as an incentive

8. Benchmarking and ranking raise feeling of competition

9. Standardized assessment enables HEls to learn from each other and cooperate 
Education for sustainable development policy: development, support, and evaluation

The most obvious reason for an assessment instrument on ESD is that managers and policy makers want to gain information about the situation in a higher education institution. This information can be used to formulate a policy towards ESD in order to implement elements of sustainable development in education and research and in order to evaluate the policy of the past years. Experiences in the Netherlands, Belgium, and other countries show that the use of an AI contributes strongly to ESD processes within the HEIs. They also show that one of the most important effects of assessment is the raising of awareness and support for ESD among the management, the staff, and the students.

\section{ESD toward the mainstream of higher education}

In the early stages of the process of implementation of sustainable development (SD) in HEIs, ESD is usually experienced as something "extra," not belonging to the main activities of the HEI. In later stages, SD usually grows to become an integrated part of the activities, the policy, and even the mission of the HEI. This is vital in order to achieve one of the goals of the DESD, that is, that ESD becomes part of the mainstream of education.

development into the mainstream of higher education, it is important that an assessment instrument on ESD can easily be integrated in the general quality management.
If ESD must become part of the mainstream, it is necessary that it also becomes a part of the quality management of the HEI. This requires tools, so that ESD can be considered as part of a Deming Cycle ("plan-do-check-act") of quality management. ${ }^{1}$ For this, an assessment instrument must exist.

\section{Transparency, certification, and benchmarking}

A strong relation exists between sustainable development and corporate social responsibility (CSR). One of the main elements of CSR is transparency; organizations explain their activities to all kinds of stakeholders and give an account of themselves, for instance, through annual CSR or SD reports or through CSR or SD pages on a website.

CSR or SD accounting enables financing organizations (e.g., a ministry of education) to evaluate the activities and results of a higher education institution. It enables potential students to select an HEI for themselves. And it enables the general public to form an opinion about the educational and societal impact of the HEI.

This status can be strengthened by a system of SD certification, as was introduced in the Netherlands by $\mathrm{DHO}$ in 2002. Some 50 educational programs in the Netherlands and in Belgium have received this certificate, which is described in greater detail below. The ESD certificate appears to be a strong incentive for ESD efforts.

Finally, sustainable development accounting based on assessment and standardized reporting may be used to compare HEIs. This opens the possibility of benchmarking and ranking HEIs regarding their ESD efforts, although no experience with this exists in the Netherlands (and possibly elsewhere) to date.

\section{Characteristics of an ESD Assessment Instrument}

\section{Four main roles of a higher education institution}

HEIs can be seen in different ways, depending on the role that is emphasized. The two core activities no doubt are education and research. Apart from that, an HEI can be seen as an organization in itself. In this role, it performs many kinds of operations: It is active as an employer, a consumer of goods, a producer of waste, etc. ${ }^{2}$ A fourth role can be described as a "member of society." In its societal role, which in some countries (e.g., Sweden) is explicitly described in educational laws and regulations, HEIs may be active in their local community, in political or societal discussions in their country, in the development of third world communities, and so on. ${ }^{3}$

A number of assessment instruments exist. ${ }^{4}$ Some of them, like the ULSF questionnaire, place much emphasis on the operations role. ${ }^{5}$ Others, such as AISHE, focus on the educational role. None of the instruments appears to focus on the assessment of the research or the societal aspects of sustainable development in HEIs.

\section{Quality management}

Because of the desire to integrate the education of sustainable development into the mainstream of higher education, it is important that an assessment instrument on ESD can easily be integrated in the general quality management $(\mathrm{QM})$. This is true on two levels.

First, there is the internal quality management of an HEI. Well-known QM tools that are used in HEIs are ISO (International Organization for Standardization, www.iso.ch) and EFQM (developed by the European Foundation for Quality Management). Specifically for the environmental management, ISO $14000^{6}$ and $\mathrm{EMAS}^{7}$ are used, and several HEIs in Europe are certified on the basis of one of those methods. ${ }^{8}$ Environmental management can be seen as one of the elements of the operations aspect of ESD. In terms of the "Triple P," it represents a part of the "Planet" aspect (see Appendix 1).

Second, there is a national level of quality management in the form of the accreditation system. In the Bologna agreement, the EU countries agreed to set up a quality assurance system, for instance an accreditation system, as a part of the creation of a European Higher Education Area. In the Netherlands and in Flanders (Vlaanderen, the Dutch speaking part of Belgium), the accreditation system is 
fully functioning, set up by the Nederlands-Vlaamse Accreditatie Organisatie (NVAO). In other countries, the development stages of the accreditation system vary.

In order to integrate the assessment of ESD in the general quality management, it will be necessary that an assessment instrument is designed along the lines of existing methods for QM. This is a complicated requirement, because the existing methods differ greatly. For instance, the fundamentals of the ISO method are very different from those of the EFQM model. Originally, ISO was primarily based on quantitative, result-oriented indicators, while EFQM focuses on qualitative, process-oriented indicators. (More recent versions of ISO also pay attention to process indicators.) In addition, it seems that the various accreditation systems in the European countries are going to differ considerably. Nevertheless, an assessment instrument for ESD has to fit with the existing QM methods or at least not contradict them.

\section{The AISHE Method}

\section{Emphasis on education}

The AISHE method, developed in 2000-2001 by the Dutch ESD network organization DHO, focuses mainly on the education aspect. This decision was made by $\mathrm{DHO}$ because, in their opinion, the educational role is the strongest way in which an HEI can contribute to SD, due to the snowball effect that education can have on society.

\section{Organizational level}

Because of its emphasis on education, the design of AISHE is aimed at the level of separate education programs within HEIs. During the testing phase in the fall of 2001, one experiment was designed to apply AISHE to a complete, large HEI (the University of Gothenburg, Sweden, with some 40,000 students). In accordance with expectations, this assessment did not turn out to be successful. Within this one university, many differences existed-in the educational methodologies, the education development policies, the stages that the integration of ESD was in, and so on. So, it appears that the educational aspect of ESD can best be assessed at a level on which a sufficient amount of homogeneity exists - a separate educational program or a group of programs (like a faculty or a department) under certain conditions. AISHE pays some (but not much) attention to the research, the operations, and the societal role of an HEI.

\section{Process orientation}

In 2000, when the development of AISHE started, some HEIs in the Netherlands were in the pioneering stage of ESD. Most of the other HEIs were not interested in ESD at that time. For this reason, it was not a good idea to construct an assessment instrument focusing on the achieved results of ESD poli- cies. Instead, it was better to focus on the process of ESD integration, in order to strengthen and encourage this process. Therefore, the qualitative, processoriented EFQM approach to quality management and assessment was better suited than the quantitative, result-oriented ISO approach. ${ }^{9,10}$ So, the EFQM model was adopted as a fundament. Another source was a QM model developed by INK, which made use of a five-point ordinal scale based on the EFQM philosophy. ${ }^{11}$ The INK model had already been transposed to a general tool for quality management in higher education, ${ }^{12,13}$ which offered a good starting point for the development of AISHE. More details about these and other fundamental choices can be found in the reports by Roorda. ${ }^{14,15}$

\section{The development project}

At the start of the development process of AISHE in the year 2000, a stakeholder analysis was made. Several groups and organizations were considered as stakeholders-for instance, HEIs and their managers and staff, students and their organizations, national HE organizations, local and national governments; as well as the professional field, including companies, labor organizations, employer organizations, and nonprofit organizations. Society in general, represented by NGOs (nongovernment organizations) such as environmental action groups and human rights groups, was also included in this list of stakeholders.

For all relevant stakeholders, representative organizations were selected, and within those organizations, representative experts were invited to become a member of a stakeholder forum. This forum, consisting of about 25 people, commented on each development step of AISHE.

First, a list of criteria was designed. After several adjustments, this list consisted of 20 criteria (Table 2). Next, the five-point ordinal scale (Table 3) was applied to each of the 20 criteria, thus resulting in an array of five times 20 descriptions. To this was added a set of procedures for the performance of an assessment, after which the tool was ready for practical tests, which took place in the second half of 2001.

More details about the structure of AISHE can be found in the AISHE book itself, ${ }^{16}$ which can be downloaded in English or Dutch (www.dho.nl/ aishe). From this website, the computer application AISHE Reporter can also be downloaded. The diagram in Figure 1 shows the results of an assessment.

\section{Testing and validation}

The AISHE method has been tested in several ways in order to validate the tool. The evaluation made use of three kinds of tests: 1.) feedback by the stakeholder forum; 2.) questionnaires for several groups, such as the management, the teaching and the nonteaching staff, and students at several different time 


\begin{tabular}{|c|c|c|c|c|}
\hline Certificate levels & 1 & 2 & 3 & 4 \\
\hline 1.1. Vision of ESD & 1 & 2 & 3 & 4 \\
\hline 1.2. ESD policy & 1 & 2 & 3 & 4 \\
\hline 1.3. Communication on ESD & 1 & 2 & 3 & 4 \\
\hline 1.4. Environmental management & 1 & 2 & 3 & 4 \\
\hline 2.1. External network for SD & & 1 & 2 & 3 \\
\hline 2.2. SD expert group & & 1 & 2 & 3 \\
\hline 2.3. ESD in staff development plan & 1 & 2 & 3 & 4 \\
\hline 2.4. SD in research, external services & & & 1 & 2 \\
\hline 3.1. SD in profile of the graduate & 1 & 2 & 3 & 4 \\
\hline 3.2. Educational methodology & 1 & 2 & 3 & 4 \\
\hline 3.3. Role of the teacher & & 1 & 2 & 3 \\
\hline 3.4. SD in student examination & 1 & 2 & 3 & 4 \\
\hline 4.1. SD in curriculum & 1 & 2 & 3 & 4 \\
\hline 4.2. Integrated problem handling & 1 & 2 & 3 & 4 \\
\hline 4.3. SD in traineeships, graduation & 1 & 2 & 3 & 4 \\
\hline 4.4. SD specialty & & & 1 & 2 \\
\hline 5.1. Appreciation by staff & & 1 & 2 & 3 \\
\hline 5.2. Appreciation by students & & 1 & 2 & 3 \\
\hline 5.3. Appreciation by professional field & & 1 & 2 & 3 \\
\hline 5.4. Appreciation by society & & 1 & 2 & 3 \\
\hline Number of certificate demands & 11 & 18 & 20 & 20 \\
\hline
\end{tabular}

\section{Table 3. General Description of the Five-Point Ordinal Scale of AISHE 1.0}

\begin{tabular}{|c|c|c|c|c|}
\hline $\begin{array}{c}\text { Stage } 1 \\
\text { Activity oriented }\end{array}$ & $\begin{array}{c}\text { Stage } 2 \\
\text { Process oriented }\end{array}$ & $\begin{array}{c}\text { Stage } 3 \\
\text { System oriented }\end{array}$ & $\begin{array}{c}\text { Stage } 4 \\
\text { Chain oriented }\end{array}$ & $\begin{array}{c}\text { Stage } 5 \\
\text { Society oriented }\end{array}$ \\
\hline $\begin{array}{l}\text { - Educational goals } \\
\text { subject oriented. } \\
\text { - The processes are } \\
\text { based on actions } \\
\text { of individual staff } \\
\text { members. } \\
\text { - Decisions are } \\
\text { usually made ad } \\
\text { hoc. }\end{array}$ & $\begin{array}{l}\text { - Educational goals } \\
\text { are related to the } \\
\text { educational } \\
\text { process as a } \\
\text { whole. } \\
\text { - Decisions are } \\
\text { made by groups } \\
\text { of professionals. }\end{array}$ & $\begin{array}{l}\text { - The goals are } \\
\text { student oriented } \\
\text { instead of } \\
\text { teacher oriented. } \\
\text { - There is an } \\
\text { organization } \\
\text { policy related to } \\
\text { (middle) long- } \\
\text { term goals. } \\
\text { - Goals are } \\
\text { formulated } \\
\text { explicitly, are } \\
\text { measured and } \\
\text { evaluated. There } \\
\text { is feedback from } \\
\text { the results. }\end{array}$ & $\begin{array}{l}\text { - The educational } \\
\text { process is seen } \\
\text { as part of a } \\
\text { chain. } \\
\text { - There is a } \\
\text { network of } \\
\text { contacts with } \\
\text { secondary } \\
\text { education and } \\
\text { with the } \\
\text { companies in } \\
\text { which the } \\
\text { graduates will } \\
\text { find their jobs. } \\
\text { The curriculum } \\
\text { is based on } \\
\text { formulated } \\
\text { qualifications of } \\
\text { professionals. }\end{array}$ & $\begin{array}{l}\text { - There is a long- } \\
\text { term strategy. } \\
\text { The policy is } \\
\text { aiming at } \\
\text { constant } \\
\text { improvement. } \\
\text { - Contacts are } \\
\text { maintained, not } \\
\text { only with direct } \\
\text { customers but } \\
\text { also with other } \\
\text { stakeholders. } \\
\text { - The organization } \\
\text { fulfills a } \\
\text { prominent role in } \\
\text { society. }\end{array}$ \\
\hline
\end{tabular}

points (e.g., before the assessment, halfway through the assessment, immediately after and two months after the assessment); and 3.) testing and retesting within one organization with several disjoint groups of participants.

Stakeholder forum. At the start of the development of AISHE, it was impossible to investigate the conceptual validity (criterion validity) and the representativity (content validity) of the method, based on exactly defined concepts, because no general consensus existed on the definition of sustainable development or its relevance in higher education. In order to create a way of testing both aspects of validity, after each developmental step of AISHE, the design was presented to the forum.

These steps were:

1. Fundamentals of the tool

2. Design of the list of criteria

3. Design of the five stages for each criterion

4. Further details: format and layout, appendices, procedures

5. Practical tests 
After each step, discussions within the forum lead to adjustments and corrections.

Practical tests. A series of practical tests of AISHE were performed in 2001 at the universities and hogescholen (i.e., universities for professional education) in the Netherlands and Sweden. These tests showed the applicability of AISHE in cases where either a separate study program was assessed or in a department consisting of several study programs that shared a clear unity in vision and educational methodology.

Investigation among participants. Before and after the assessments, the participants of the practical tests were interviewed using standardized questionnaires. In this way, aspects of validity, reliability, and applicability of AISHE were investigated. In addition, separate questionnaires were answered by the management of the assessed organizations. Appendix 2 shows some examples of the questions asked. The questions were aimed at investigating validity-concept validity, representativity; reliability-internal consistency; and applicability-unambiguousness, practicability, investments, efficacy, acceptability.

The results of the investigation indicated that AISHE sufficed in most respects. A number of smaller problems that occurred gave rise to suitable adjustments.

Equivalence. Another aspect of reliability-equivalence-was investigated when, in one university, two assessments were performed on two consecutive days within the same study program. The two groups of participants were completely separate, and both had an equivalent constitution. The second group did not know the results of the first group. The results of both assessments with respect to the present situation were nearly identical. The results of the desired situation differed somewhat more, but did not show remarkable differences. Interestingly, the policy ambition of both groups was almost identical. The conclusion was that the equivalence of AISHE was sufficiently proven.

Concurrent validity. The concurrent validity of AISHE has not been investigated. For such an investigation, other assessment methods would be necessary, aiming at measuring the same things as AISHE, in order to decide whether they render the same results as AISHE does. Such methods did not exist at the time of the development of AISHE, and this is still the case. So, such an investigation is impossible.

After AISHE's validity was proven in this way, the tool was published and made available on the website (www.dho.nl/aishe). Since that time, HEIs are free to download all necessary documents and tools. They are encouraged to use AISHE by themselves or to invite $\mathrm{DHO}$ to send an assessor and organize an assessment.

\section{Implementation of AISHE}

In order to streamline and standardize the application of AISHE, a number of items have been added.

- The assessment procedure was published.

- A checklist was made to investigate whether a combination of educational programs may be assessed together.

- A computer application, AISHE Reporter, was made for the automatic production of the report of the assessment. The application (functioning in English and in Dutch) can be downloaded from (www.dho.nl/aishe).

- A three-day training course for assessors was designed and is organized annually.

- For the participants in this course, a followup training and examination program was set up, leading to the possibility of acquiring an AISHE assessor certificate.

The assessment procedure

The assessment takes from five to six hours for a group of about 15 people (Table 4), chaired by the assessor. After the AISHE book has been distributed and the model has been explained to the participants, they are asked to read a part of the AISHE book that contains the descriptions of the five stages for all criteria. While doing this individually, they compare this to their own organization (e.g., an education program or a faculty of their university), and select the stage that, in their personal opinion, most resembles the situation in their organization. At the end, they write their conclusions down on a form and hand it to the assessment leader, who combines the conclusions of all on one composite form.

Next, a consensus meeting takes place in which all of the participants are present. At the beginning, the copied composite form is distributed. As before, every participant has the AISHE book, in which they

Table 4. Some Elements of the AISHE Assessment Procedure

- Group of about 15 participants: a representative delegation of management teaching and non-teaching staff, students

- Assessment is only possible if participants have at least elementary knowledge of sustainable development, if not, there is the option of an introductory workshop by $\mathrm{DHO}$.

- Time use: $\sim 5-6$ hours-i.e., $\sim 30 \mathrm{~min}$ introduction by assessor, $\sim 45$ min individual scoring; $4-5$ hours consensus meeting

- ESD certificate can only be awarded if the assessment was chaired by a certified AISHE assessor.

- The use of the computer application AISHE Reporter is obligatory in order to ensure a well-structured report.

- Follow-up: ESD policy determination by management within 1 week after assessment, if desired with consultancy by $\mathrm{DHO}$ 
wrote their own scores and annotations. The criteria are discussed one by one. All participants have an equal weight in the discussions, in the proceeding of the conversation, and in the decision making. On a basis of intrinsic reasoning, a common conclusion is looked for about the right scores for the organization.

If possible, decisions are made based on consensus. If, however, for some criterion no consensus can be reached, the assessor will conclude that, of all proposed scores, the lowest is the one agreed upon. This is because a higher score can only definitively be realized if all participants agree with it. In no case at all, decisions are made by voting.

\section{Desired situation, priorities, and policy proposals}

During the discussion of the criteria, it is natural for a number of possible improvement points to arise. This enables the group to formulate a desired situation for each criterion. This desired situation is defined not only in the form of a stage to be reached but also in the form of a series of concrete targets and associated activities that lead to the desired stage. In order to guarantee that the necessary level of concreteness is achieved, at the beginning of the consensus meeting, an exact date is chosen on which this desired situation is to be realized. Usually, the date selected is one to two years after the assessment.

After the policy intentions are thus defined for all 20 criteria, a large list of goals and activities is formed for the coming period. Usually this list is long, and so in the end a small number of priorities are appointed.

\section{Results}

At the end, the assessment results consist of the following:

- A report containing a description of the present situation in the form of a stage number and a verbal description for each criterion;

- A similar description of the desired situation, giving ample opportunity to the management to formulate an SD policy plan;

- A date on which this desired situation has to be reached;

- A list of first priorities, which are considered crucial for concluding if the policy has been successful;

- In practically all cases, a growing awareness, enthusiasm, and support for SD within the group of participants;

- Indications for the management about which staff members may be given responsibility for certain aspects of the SD policy plan.

\section{Overall indicators}

In the AISHE assessment report, a small group of global indicators is calculated.
In the years 2001 to (roughly) 2005, the median of the 20 scores was, in most cases, stage 1 . In many of the assessments, the participants defined a desired situation with a median of 2 . In the last few years, more and more assessments resulted in a median of stage 2 and a desired situation with a median of stage 3. This shows that real progress is being made.

The plan-do balance is defined as the difference between the added scores of the "do" part (criteria 3.1 to 4.4 ) and those of the "plan" part (criteria 1.1 to 2.4). If this indicator is far below zero, this indicates that the university is making a lot of plans but is not very successful in implementing the plans in the education. If, on the other hand, the indicator is very high above zero, much has been achieved with respect to the education, but there is not much support from the management; there is therefore a risk that the achievements may vanish in the near future because they are not anchored in university policy.

The policy ambition is calculated by adding all scores of the desired situation and subtracting the sum of the scores of the present situation. Policy ambitions appear to vary between about five and 20, with an average of about 12. An interesting phenomenon is that usually the ambition is higher when the present situation is higher; it seems that the forerunners tend to want to preserve their front position.

The distance to a certificate is defined as the sum of the differences between the demands of the certificate and the scores of the (present or desired) situation, only if those scores are lower than the demands. If some scores are equal to or higher than the demands, those scores do not influence the distance to the certificate. If the distance to certificate equals zero, in principle (i.e., apart from a final check) the certificate has been achieved.

\section{Quality cycle}

During the first year of AISHE implementation (2002), it was discovered a number of times that several months after an assessment was performed, the HEI had not made effective use of the assessment results. As a consequence, the enthusiasm and support that the assessment had initially raised disappeared, and many of the participants, including the management, had forgotten most of the subjects that were discussed. Thus the effects of the assessment were small or nil. From this experience it became clear that it is vital to use the results soon after the assessment is done in order to design a concrete ESD policy plan (either as a separate plan or as a part of a general policy). Therefore, in all cases in which an HEI and DHO prepare an assessment together, DHO emphasizes that a meeting of the management should take place at the most one week after the assessment. Support from DHO is offered, and if accepted, a DHO consultant takes part in the decision process. 
Ideally, this process leads to a policy plan to be followed for the next one or more years. In this way, a quality cycle (plan-do-check-act) is started. The "plan" phase is formed by the assessment and the formulation of the policy plan. The "do" phase consists of the activities that follow. The cycle can be closed by repeating the AISHE assessment to evaluate the results ("check") and by taking the next actions for further improvements ("act"). In this way, AISHE contributes to a continuous improvement with respect to ESD.

\section{Present situation}

To date (i.e., as of this writing), AISHE assessments have been done in the Netherlands, Belgium, and Sweden. Assessments in Finland and other European countries are in preparation. A large ESD project in Brazil is starting up in which AISHE, assisted by $\mathrm{DHO}$, will be used in a range of HEIs.

\section{AISHE Certification and Accreditation}

A certification system based on AISHE was designed by DHO. Educational programs in HEIs can acquire the ESD certificate on several levels, which together form a "star system." The requirements of the four different star levels can be seen in Table 2 (see also Fig. 1). In order to acquire the certificate, educational programs have to do an AISHE assessment chaired by a certified AISHE auditor selected by DHO. The resulting report is checked by the DHO Certificate Commission. If necessary, an extra visitation to the $\mathrm{HEI}$ is made by this commission. If the commission confirms the results of the AISHE assessment, the certificate is awarded.

Between 2002 and 2007, about 60 educational programs in about 12 HEIs in the Netherlands and Belgium received the certificate, mostly on the first level; some 10 of them received the second-level certificate.

At the end of 2006, an agreement was made with the Dutch and Flemish national organization for the accreditation of higher education (NVAO). This action resulted in the formal recognition of AISHE by NVAO, and to the introduction of a special recognition of sustainable development, to be assessed with AISHE, as a formal part of the accreditation of $\mathrm{HE}$

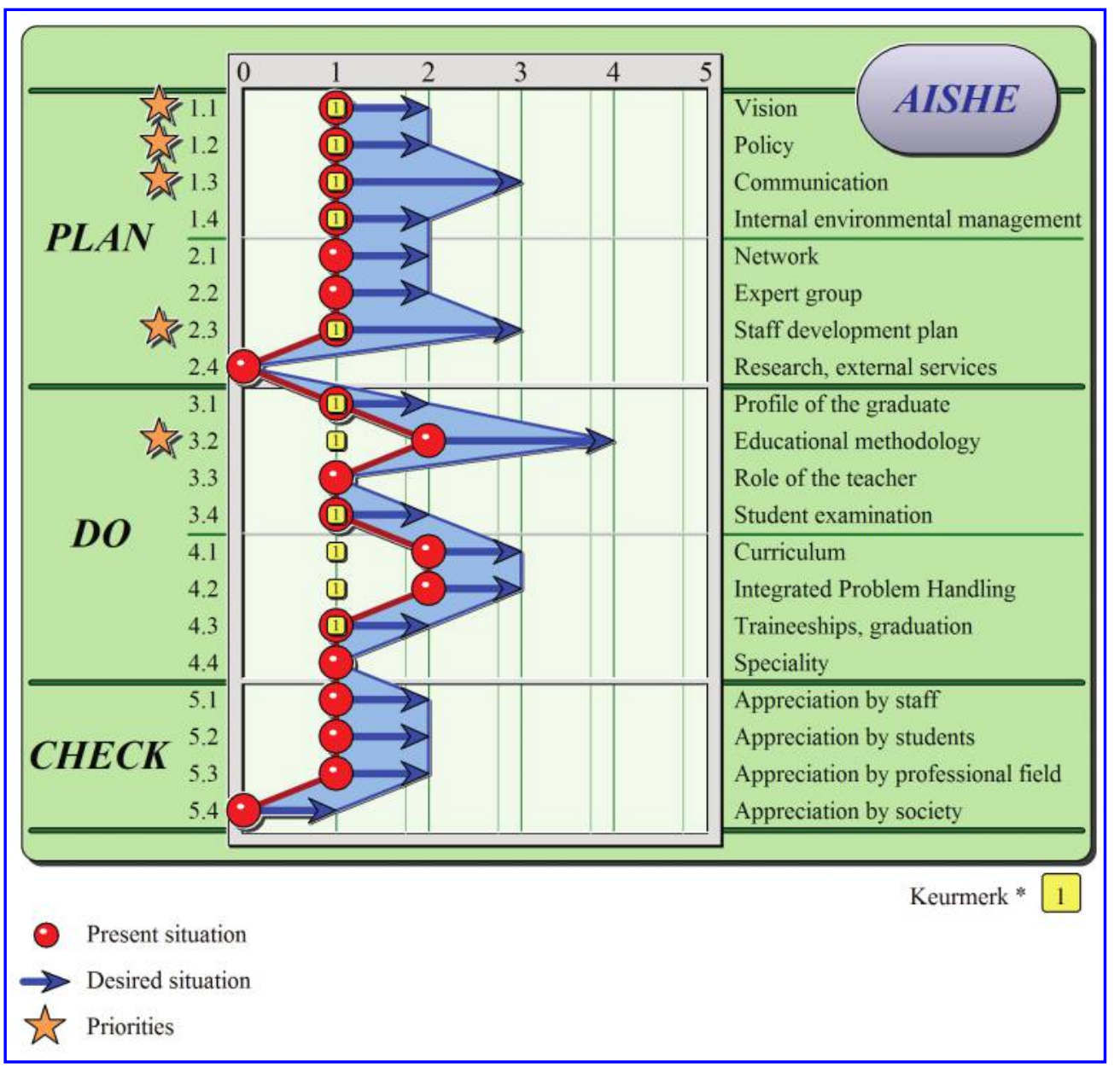

Fig. 1. Results of an AISHE 1.0 assessment. The demands of the first certificate are also shown. (Figure was constructed with AISHE Reporter.) 
in the Netherlands. In 2007, educational programs will be awarded this special recognition if they have obtained the second level of the DHO Certificate of Sustainable Development in Higher Education, since the assessment results prove that this is the present level of excellence. DHO and NVAO have agreed that together they will check this required level annually, and if necessary, they will raise the threshold level. In early 2007 the first three educational programs actually received this special recognition, as a part of their accreditation.

The DHO Certificate is valid for three years. This is exactly half of the validity period of the accreditation of higher education in the Netherlands, which is six years. This makes it possible to complete two complete quality cycles of ESD during one accreditation cycle.

\section{Practical Experiences}

By early 2007, more than 100 assessments had been done. Some of them were done by the universities themselves, using the equipment from the $\mathrm{DHO}$ website but without the assistance of DHO itself. Those assessments are not valid for certification. Most of the assessments, however, are chaired by a certified assessor. From the assessments done so far, some interesting conclusions can be drawn.

AISHE is used in various kinds of disciplines. Among them are:

- Science and technology departments and programs (e.g., physics, chemistry, architecture, civil and mechanical engineering, ICT);

- Economical and law departments and programs (e.g., economics, financial studies, management studies, law studies, real estate studies);

- Environmental science and technology;

- Social studies;

- Agriculture and biology;

- Health departments and programs (e.g., medicine, nursing, obstetrics);

- Educational studies (e.g., primary teacher education, technical professional teacher education).

Communication about SD (criterion 1.3) is nearly always a main point for improvement (i.e., it is given high priority). Usually, many criteria are less than optimal because of a lack of effective communication between the management and staff, among staff members themselves, with other people or parties involved (such as the professional field), and, especially, between the university and the students.

Improvements in the vision and policy about SD (criteria 1.1 and 1.2) are given a high priority in almost all assessments. The vision and policy often lack explicit mention of SD. In some cases, explicit reference is made to related subjects, such as ethics, responsibility, and societal role. When SD is mentioned implicitly or explicitly, in most cases the texts are regarded by the assessment group as a dead letter. Thus, an improvement often regarded as vital is the explicit formulation of SD in the mission statement, and policy plans in such a way that there are real implications for the HEI activities and the education.

Usually a wide variety of opinions is observed in the individuals. It is not uncommon that the opinions about a criterion vary from stage 1 to stage 4 . It appears that there are two main causes for this: a lack of effective communication and a difference of opinion about the concept of SD and the meaning of it in relation to the education. Nevertheless, nearly always it appears to be possible to find a consensus on all criteria.

Also, repeatedly found is that the manager thinks more optimistically regarding a number of criteria than the other participants do. This, too, is usually caused by a lack of communication; often the manager knows much more about ongoing management processes but knows less about the effectiveness of them than do the staff and, especially, the students.

Consensus is not always reached on a stage where originally the majority of participants thought it should be. There are interesting examples in which it occurred that a stage was concluded to be even lower than everyone expected. This was usually caused by a critical examination of the existing opinions by the assessor selected by $\mathrm{DHO}$.

More and more universities are using the requirements of the various certificate levels as guidelines for their ESD policy. Usually this is done by comparing the desired situation, formulated during an assessment, with the certificate demands. If the desired situation is close but not equal to the set of requirements of a certain level, the goals are adapted to receive the certificate at the end of the policy period. In other cases, the long-term strategy is formulated using, for instance, the demands of the level 3 certificate, even if the university department involved has just (or not quite) acquired level 1.

This shows that the certificate is an effective means to strengthen the process of integration of sustainable development in HE, which has been confirmed in interviews with managers and teachers. The certificate appears to be experienced as an incentive.

\section{Case 1: A study program in applied science- certificate progress}

After an assessment in 2002, a study program in applied science received its first certificate of sustainable development in higher education. Three years later, it did another assessment, and at that time it was among the first universities to be awarded the two-star certificate. It is interesting to see how this 
progress took place. The overall results of both assessments are shown in Table 5.

Although the actual results in 2005 were somewhat lower than was desired in 2002, the difference was not great. In the desired situation formulated in 2002, the level 2 certificate would nearly be reached. In reality, this certificate was reached in 2005, so the real improvements in three years surpassed the planned improvements, especially in those aspects where the certificate put its demands. The exact scores are given in Figure 2.

In 2002 an imbalance existed between the plans and the realization in the education. The plan-do balance was negative: Until 2002, more efforts were put on the development of the vision and preparations than on the actual realization of ESD. Although the plans made in 2002 did not try to harmonize this balance, this was realized in 2005, thus making it possible to receive the second level certificate.

The plans made in 2005 will, if realized some years later, nearly but not fully lead to a level 3 certificate. It will be interesting to see if this level will act as an incentive in the coming years, although the management of the university department indicated that this is not the intention.

\section{Case 2: An economics study program- communication}

In a large Dutch university for professional education, the staff of an economics study program was working on the implementation of ESD, and $\mathrm{DHO}$ was asked to perform an AISHE assessment. It appeared that the economics program did not score very well compared to other universities. The median of the scores was 1 . The program failed to meet

Table 5. The Case of a Study Procedure in Applied Science

\begin{tabular}{|l|cc|cc|} 
& 2002 present & 2002 desired & 2005 present & 2005 desired \\
\hline Total score & 28 & 42 & 38.5 & 55 \\
Median & 1.25 & 2 & 2 & 0 \\
Plan-do-balance & -6 & -7 & 0.5 & 16.5 \\
Policy ambition & 14 & 0 & 0 \\
Distance to certificate 1 & 0 & 0 & 0 & 1 \\
Distance to certificate 2 & 7.5 & 1 & 11.5 & 0 \\
Distance to certificate 3 & 21 & 10 & & \\
Distance to certificate 4 & & & & 0 \\
\hline
\end{tabular}

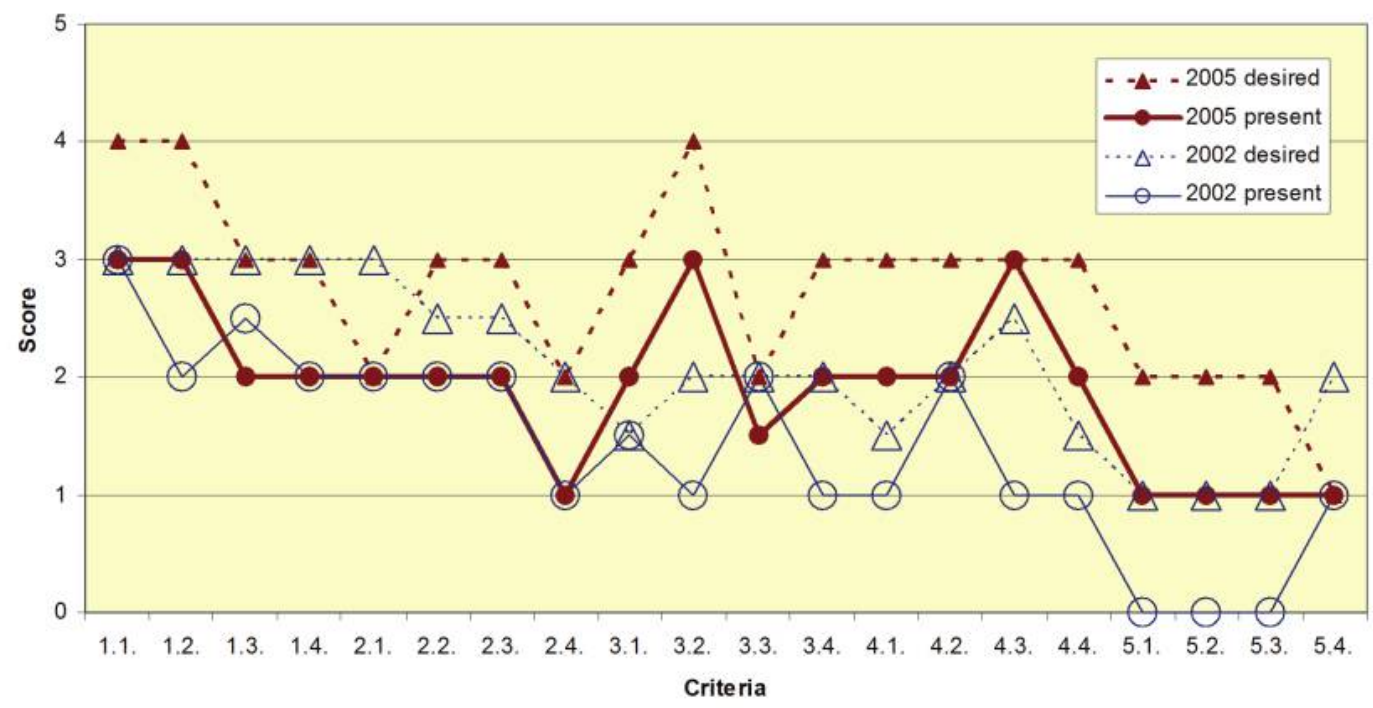

Fig. 2. Results of two assessments within a department of applied sciences. 
the demands of the first certificate. The high priorities that were selected at the end of the assessment were criteria 1.1, 1.2, and 1.3-that is, vision, policy, and communication-as well as in criterion 4.1curriculum.

During the next half-year, the department team worked on the implementation of the goals of the desired situation. The vision and the policy toward SD were strengthened by participating in a university-wide process of redesigning the mission statement. The redesign of the curriculum resulted in a basic module on sustainable development for the propaedeutic year, a large student project on SD in the second year, and adaptations of the educational methodology. However, the team was not satisfied. attention had been given to SD once. It had been on the agenda of some meetings. The department team was in doubt about possible next steps. As expressed by the manager, "We have communicated about SD in every way we could think of-so what can we do next?"

Together with DHO consultants, the situation was analyzed. It was concluded that a systematic communication with the university board and the other university departments could lead to the desired, more explicit formulation of the university vision on SD, based on the new mission statement. Next, systematic communication with the teaching staff, the students, and the professional field could lead to ideas about the integration of SD in the curricula.

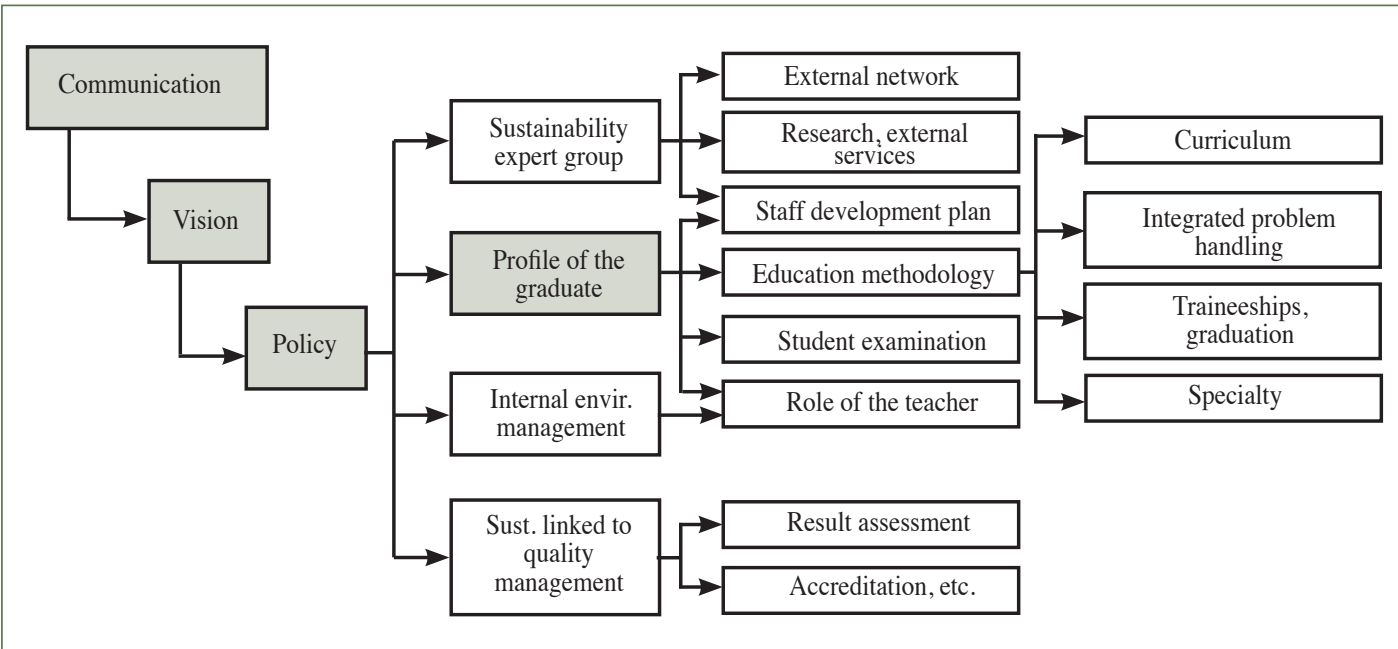

Fig. 3. A systematic approach to the development of sustainability in the organization and education and the start of a communication plan. The four shaded boxes represent the four highest priorities, selected during the audit.

SD had not yet been integrated into the curriculum in a systematic way: The sustainable elements were not logically connected as a thread throughout the curriculum. The new university mission statement contained some SD-related elements, such as ethics and professional responsibility, but SD itself was not mentioned explicitly, and the text was rather abstract; it was difficult to draw conclusions from it with respect to a policy or to concrete activities. A major problem, according to the manager, was the definition of the professional profile of the future graduates (criterion 3.1); he and his team experienced a gap between the university vision, as formulated in the mission statement, and the professional profile of the economics program. If it would be possible to make the vision more explicit, namely, to operationalize it, then it could be used to formulate the professional profile and, thereafter, to redesign the curriculum in such a way that SD could be integrated systematically.

In the area of communications, some achievements were made but these were rather ad hoc and not executed in a systematic way. In the university magazine,
Instead of the ad hoc communication of the former half year, a communication plan was needed as a first step.

A simple communication plan was designed, based on two dimensions. One dimension described reasons for communication, such as "give information," "receive information," "generate new ideas together," "create support," and so on. The other dimension was based on a stakeholder analysis-for instance, teaching staff, students, management, PR department, professional field, public media, government.

Thus, the communication plan was used as a first step toward a total SD policy, which is shown in Figure 3. The economics team worked along these lines for some years. After a second AISHE assessment in 2005, the department was awarded a level 1 certificate for SD in HE.

\section{Case 3: An environmental science program-} identity crisis

For almost all of the university programs in environmental science and technology in the Netherlands, 
the number of students had been decreasing strongly in the years around 2000. At the same time, investigations in the professional field indicated that the need for environmental experts would diminish in the next few years. Because of this situation, several field studies were performed. Dröge and Schoot Uiterkamp ${ }^{17}$ looked at the future needs of the professional field for environmentalists and attempted to redefine the professional competencies they would need. In another investigation, a commission of the Dutch Association of Universities for Professional Education (HBO-Raad) looked at the question of what the relation should be between the environmental study program and SD, regarding the fact that more non-environmental university programs were already integrating aspects of SD in the curriculum. It was determined the environmental programs were "losing territory."18

In the final report of this latter investigation, it was recommended that three major profiles were to be discerned for the future environmental experts: the consultant, the researcher, and the process manager. For all of those profiles, an interdisciplinary role as part of a team of various disciplines would be vital.

After the report was published, many of the universities with environmental programs were searching for a new definition of their program, a new raison d'etre. An AISHE audit was done in one of the environmental programs. Not surprisingly, the results showed an emphasis on the need for the development of a new vision. The high priorities for improvement were chosen for criteria 1.1 to 1.3 (vision, policy, communication), 2.3 (staff development), 3.1 (profile of the graduate), and 4.1 (curriculum). The central problem was described in the assessment report:

A 'kind of a' vision exists, but the contents are not formulated very explicitly. There is much emphasis on environmental subjects, and not enough attention to sustainable development in general. That is to say, sustainability is interpreted too narrowly as 'mainly environmental matters.' ... It is virtually impossible to check whether the students acquire the right and enough professional competencies, because the staff team hardly has an idea about what kind of professional competencies related to sustainable development they should be teaching.

The ambiguity regarding the role of the environmental professional discussed during the audit appeared to focus on two different views on the professional role of the future graduates. The above mentioned HBO-Raad report had emphasized an interdisciplinary role, and this was interpreted by some team members as a recommendation to see the environmental expert as specializing in interdisciplinarity, as a "spider in a web," or as the one who was going to connect all kinds of other specialists with each other. In contrast, other team members thought of quite another interdisciplinary role in which the environmentalist would still be a specialist in his own field and would function as just one of the members of an interdisciplinary team. Figure 4 shows the distinction between the two visions.

After this difference of view was discovered, clarified, and understood by all, the team concluded that it was possible to structure a decision process as a step-by-step approach. First, decisions about the profile of the graduate should be made, especially a fundamental choice between the two possible roles of the environmentalist. From there, a vision about the relevance of SD for the study program could be developed, followed by a policy plan leading to curriculum and staff development plans for sustainability subjects.

Prior to that, it was vital to develop a good plan for communication with all of the stakeholders. Only if there were a solid communication structure, guaranteeing that all interests of the professional field, NGOs, governments, and other stakeholders would get the right attention, could it be expected that a valid and durable profile of the graduate be developed.

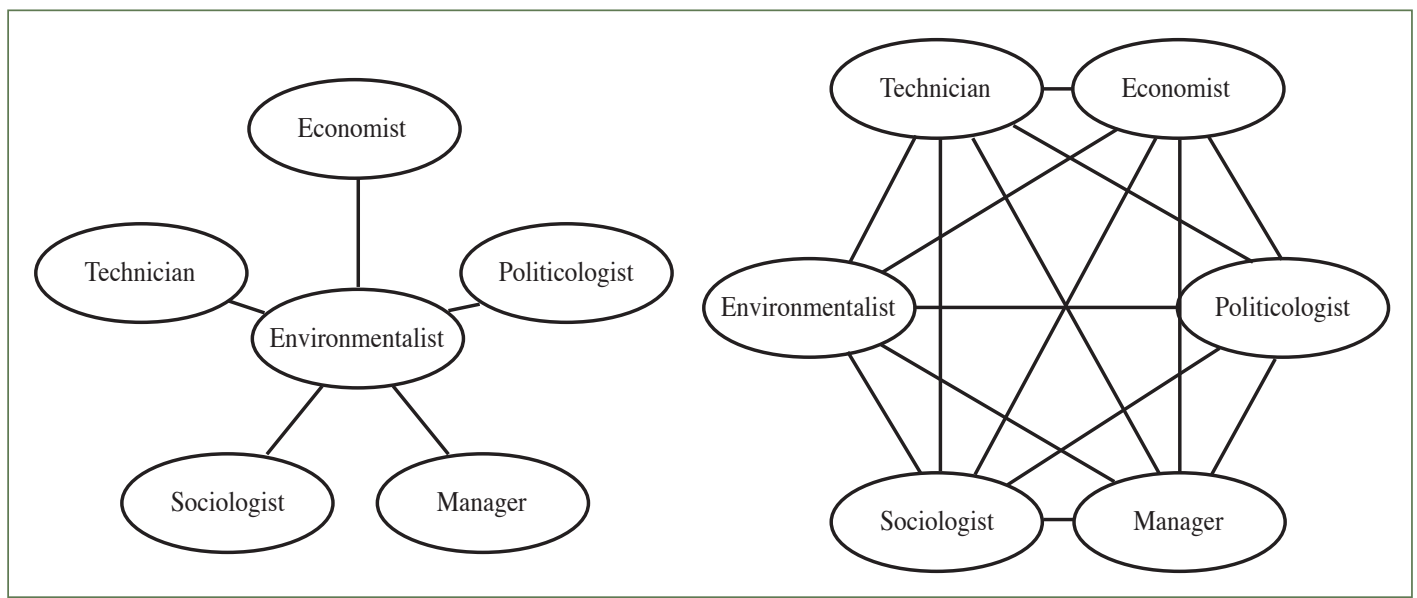

Fig. 4. Two visions of the interdisciplinary role of the environmental professional. 
As a consequence, a development scheme was designed which, superficially, resembles the one shown in the earlier case of the economical program (case 2), but in reality differs fundamentally. This is shown most clearly by the different position of the "profile of the graduate" (Fig. 5).

Another major difference between the two cases was that in the case of the economics department, the starting point of the process was the internal communication, between the board, the management, the educational staff, and the students. In the case of the environmental studies, the starting point was the external communication, with stakeholders in the professional field and in society in general. ber of such quantitative indicators to AISHE. An updated version of AISHE should thus probably consist of a combination of qualitative, process-oriented, and quantitative result-oriented indicators.

The introduction of competency-oriented education in a number of countries has had a major influence on HE. The same is true for the introduction of the major-minor system and the bachelor-master system, both following the Bologna agreement. As a consequence, there is a trend toward individual learning routes, causing the dividing lines between educational programs to disappear. Some parts of AISHE are not adapted to this new development.

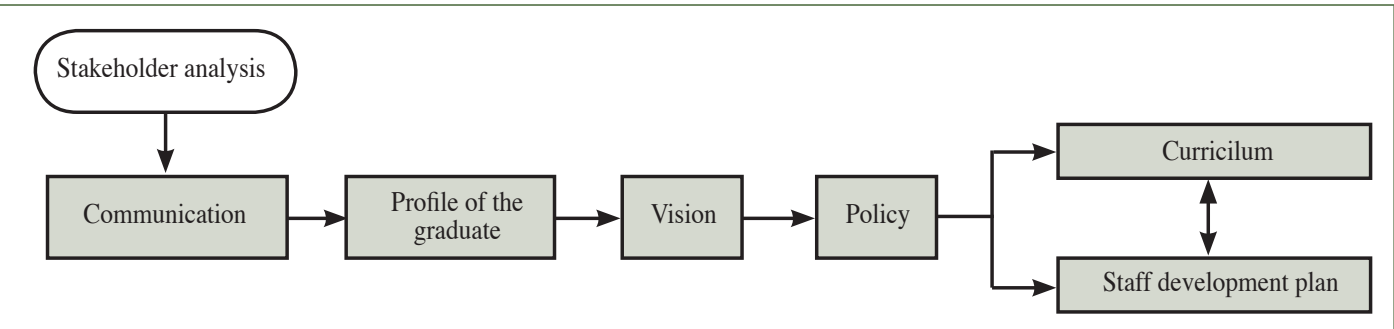

Fig. 5. Development scheme for the environmental program.

\section{Future Developments}

\section{Higher education in evolution}

Since AISHE was launched at the end of 2001, many things have changed in higher education. One of the changes is the process of internationalization in Europe and elsewhere. The Bologna agreement introduced the European Higher Education Area, leading to more international cooperation between HEIs. This implores an international cooperation on ESD too, which makes it relevant to compare HEIs across borders. This calls for an assessment and certification system with international recognition and a shared ownership by a group of ESD organizations in various countries. Besides, the $\mathrm{EU}$ introduction of $\mathrm{HE}$ accreditation brought many changes in the quality management of HEIs, and AISHE is not optimally adjusted to these new developments. Both changes (internationalization and accreditation) are reasons for updating AISHE, this time with international cooperation.

At the beginning of the 21st century, many HEIs were in a pioneering stage with respect to ESD. For this reason, the qualitative, process-oriented EFQM approach of QM was best suited. Since then, more HEIs have reached solid results regarding ESD, although much more will have to be achieved, even by the forerunners, in order to meet the goals of the DESD. Therefore, the EFQM approach of AISHE is still successful and cannot be missed; at the same time, however, a number of result-oriented indicators, possibly of a quantitative nature, will be useful. Some HEIs have asked DHO to add a limited num-
Specifically in the Dutch hogescholen, the introduction of specialist lectors, who have a role comparable to the professors in academic universities, strengthened the emphasis on research in those institutions.

\section{Practical considerations}

Other reasons for an update of AISHE are based on the practical experiences with the tool. Some users appear to object to some AISHE criteria, especially 2.2 (expert group), 2.4 (research \& external services), and 4.4 (speciality). They experience these criteria as forcing them in the direction of a certain prescribed ESD strategy.

Sometimes assessments develop problematically, particularly if the participants have no clear ideas of the meaning of sustainable development. In those cases, the discussion of, for instance, criterion 1.1 (vision) is troublesome, and scores may be invalid. Perhaps this can be avoided by the introduction of a short preliminary test in order to check if an AISHE assessment is possible. If not, some introductory workshop on SD and ESD will be necessary.

In the eyes of some HEIs, an AISHE assessment takes too much time or requires too many participants. On the other hand, some HEIs would like to enhance AISHE in order to get more detailed results. These conflicting wishes can be solved by giving AISHE a modular structure, enabling the HEIs to select the parts they want. The consequences of this modular structure for the certification system will have to be investigated.

Finally, it would be good if the AISHE reporting tool could be used to enable and tempt universities to 
publish an annual sustainability report and work on a university-wide sustainability strategy. This would contribute to the transparency and accountability of higher education.

\section{The AISHE 2.0 project, 2007-2010}

At the start of 2007, an international group was formed to update AISHE. The renewed assessment instrument will be called AISHE 2.0. Because of the need to apply AISHE on several organizational levels, the tool will be modular in structure. The four modules reflect the four roles of HEIs. The project will also lead to an international certification system for sustainable development in higher education. The project partners, from 13 different countries, are either HEIs or network organizations of ESD. Together they represent several hundred universities.

Other partners are welcome during the project, for instance, to perform practical tests with the new tool. If all goes according to plan, AISHE 2.0 will be published in 2010.

\section{References}

1. Deming WE. Out of the Crisis. MIT Press, Cambridge, 1986.

2. Clugston RM, and Calder W. Critical dimensions of sustainability in higher education. In: Sustainability and University Life, W. Leal Filho (ed.). Peter Lang, Frankfurt, 2000, pp. 31-46.

3. Megerle A, and Megerle H. University support to local and regional agenda initiatives for sustainable development. In: Sustainability and University Life, W. Leal Filho (ed.). Peter Lang, Frankfurt, 2000.

4. Shriberg M. Institutional assessment tools for sustainability in higher education. Intl J Sustainability Higher Education 2002;3(3):254-270.

5. Calder W, Clugston RM, and Rogers T. Sustainability assessment at institutions of higher education. ULSF: The Declaration 1999;3(2). Sustainability Assessment Questionnaire is downloadable: www.ulsf.org

6. Fisher RM. Applying ISO 14001 as a business tool for campus sustainability: a case study from New Zealand. Intl J Sustainability Higher Education 2003;4(2):138-150.

7. European Commission, Council Regulation 1836/93. EMAS-Environmental Management Systems, 1993.

8. Delakowitz B, and Hoffman A. The Hochschule Zittau-Görlitz: Germany's first registered environmental management (EMAS) at an institu- tion of higher education. Intl J Sustainability Higher Education 2000;1(1):35-47.

9. European Foundation for Quality Management. EFQM Model, 1991: www.efqm.org

10. van Nuland Y, Broux G, Crets L, de Cleyn W, Legrand J, Majoor G, and Vleminkx G. Excellent, a Guide for the Implementation of the EFQM-Excellence Model. Comatech, Blanden, Belgium, 2000.

11. INK. Gids voor toepassing van het INK-managementmodel. INK's Hertogenbosch, Netherlands, 2000: www.ink.nl

12. HBO Expert Group. Method for Improving the Quality of Higher Education Based on the EFQM Model, 3rd version. Hanzehogeschool (representative), Groningen, Netherlands, 1999. Translation of Expertgroep HBO.

13. Van Schaik M, Van Kemenade E, Hengeveld F, and Inklaar Y. The EFQM based method for continuous quality improvement adapted to higher education. Proceedings of the EAIR Forum, San Sebastian, Spain, 1998.

14. Roorda N. Assessment and policy development of sustainability in higher education with AISHE. In: Teaching Sustainability at Universities, Walter Leal Filho (ed.). Peter Lang, Frankfurt, 2002, pp. 459-486.

15. Roorda N. Policy development for sustainability in higher education-results of AISHE audits. In: Higher Education and the Challenge of Sustainability, P.B. Corcoran and A.E.J. Wals (eds.). Kluwer, Dordrecht, 2004, pp. 305-318.

16. Roorda N. AISHE-Assessmenting Instrument for Sustainability in Higher Education. Stichting Duurzaam Hoger Onderwijs (DHO), Amsterdam, 2001.

17. Dröge F, and Schoot Uiterkamp T. Higher environmental education and the environmental labour market in the Netherlands-a survey of the influence of internal and external factors on higher education environmental programmes and the labour market for environmental professionals in the countries of the European Union. ICM/ ESSENCE Network, Country Report, VSNU, Ulrecht, 2001.

18. HBO-Raad: Van milieu tot duurzaamheid. Eindrapport van de Verkenningscommissie Milieuopleidingen. HBO-Raad, The Haag, 2000.

Address reprint requests to:

Niko Roorda

DHO

The Netherlands

E-mail: nikoroorda@dho.nl 


\section{APPENDIX 1 \\ POSSIBLE ELEMENTS OF ESD ASSESSMENT}

\section{Mission}

- Mission and vision on ESD

- Policy on ESD

- Leadership

- Communication on ESD (internal and external)

- SD and quality management

- Stakeholders' appreciation of ESD policy

- Assignment of a sustainability coordinator (staff function related to the board)

- Transparency: SD and CSR reporting

\section{Operations}

People

- Care for personnel, human resource management

- Working conditions

- Staff and student policy regarding women, immigrants, and disabled

- Protection against sexual intimidation, violence, and discrimination

- Policy regarding health of staff and students

- Employment policy, relation with mission

-Appreciation assessment among staff and students (in general, as well as regarding ESD policy)

Planet

- Sustainable building (new and existing buildings)

- Energy consumption (savings, use of sustainable energy)

- Water consumption (incl. "gray" water system)

- Effects on the neighborhood (smell, sound, safety, traffic, and parking nuisance)

- Traffic (of staff, students, goods)

- Procurement (paper, laboratory equipment, catering)

- Waste (separation, prevention, reuse)

- Garden management

- Communication on environmental management (inventory of wishes and complaints, appreciation assessment)

- Effectiveness of environmental policy

- Overall (environmental reporting, environmental management system, certification based on ISO 14000 or EMAS, for example)

Profit

- Investments for SD, possibly longer cost recovery periods

- Savings (e.g., through reuse or economical use of energy and materials)

- Long-term strategy

- Accreditation: realization of the HEI mission, special recognition or certification

- Effects of SD on image, PR, and marketing

\section{Education}

Staff

- Basic knowledge of staff about SD and staff development plan

- Specialist SD expertise of staff members

- ESD "frontrunner" team

- Use and anchoring of relations with professional field

- Allocation of facilities for ESD development (e.g., time, competencies, responsibility, timetable freedom, training)

\section{Curriculum}

- SD in professional competencies and academic targets, relation to institutional mission

- SD in curriculum related to professional competencies and academic targets

- Educational methodology: suitable for ESD (e.g., self-responsible learning, problem-oriented learning, project education, individual learning routes)

- Basic module on and introduction to SD 
- Integration of SD within existing curriculum (SD as a leitmotiv)

- Which SD subjects are obligatory, which are optional? (e.g., major-minor)

- Interdisciplinary and transdisciplinary education

- Professional responsibility of the student (as a future professional)

- SD as an element of examination and evaluation of student performances

- SD as an element of traineeships

- SD as an element of graduation

\section{Research}

Researchers

- Research dedicated to aspects of SD and CSR

- SD as a main subject or as an aspect of the job description

- Interdisciplinary/transdisciplinary cooperation between researchers

- Transfer of SD expertise of researchers to specialist SD teachers and to teachers in general

-Contributions by researchers of SD aspects in curriculum development

\section{Students and alumni}

- SD as an aspect during traineeship research and graduation projects

- Interdisciplinary/transdisciplinary graduation projects

- Assessment of need for SD and CSR within professional field

\section{Institution, board}

- Stimulating Ph.D. research on SD by employees

- Cooperation with external centers of SD expertise, for instance, with a Regional Centre of Expertise (RCE)

- International cooperation between HEIs on ESD

\section{Society}

- Implementation of societal role, based on the mission, through an institutional center of SD expertise

- SD consultancy for companies, governments, NGOs, and the general public

- Participation in national DESD implementation programs

- Participation in local Agenda 21 programs

- Participation in public discussions on SD-related subjects

- Participation in Third World development programs

- Subsidizing local or global development programs

- Assistance with education development on SD in primary and secondary education

- Training of teachers in primary and secondary education in own and foreign countries

While making no attempt to be complete, this list offers some ideas and suggestions.

\section{APPENDIX 2 \\ EXAMPLES OF QUESTIONNAIRE ITEMS}

Before the AISHE assessment (but after the introduction)

- The goals of the AISHE assessment are clear to me.

- The procedure to be followed is clear to me.

- I have a clear image of what is expected of me during the assessment process.

- I have a clear expectation of the usefulness for me and/or our organization of the AISHE process and the results.

After the individual scoring, but before the consensus meeting

- The time that I spent on the individual scoring was acceptable.

- The AISHE criteria and their descriptions were clear to me.

- For each criterion, it was no problem for me to recognize the stage our organization is in.

- The relevance of AISHE for our education and our organization is clear.

\section{After the assessment}

- The AISHE assessment process went well.

- The constitution of the participant group is representative for the investigated organization.

- The descriptions of the criteria and of the corresponding five-stage descriptions are clear. 
- Each criterion of AISHE is relevant with respect to sustainability in higher education.

- The criteria differ enough from each other.

- The criteria complement each other and they do not contradict each other.

- To the various aspects of sustainable higher education, the criteria attribute the right relative weights.

- Together (i.e., seen in its entirety) the criteria of AISHE form a complete and correct description of sustainable development with respect to higher education.

- The results present a correct image of the actual situation with respect to sustainability in our education.

- The results present a correct image of the actual situation with respect to sustainability in our organization.

- For each criterion, it was no problem to recognize the stage our organization is currently in.

- This assessment changed my view on the present situation and the future possibilities with respect to sustainability in our organization and our education.

- I expect that the results will contribute to the development and the realization of a policy with respect to sustainability.

After the assessment, specifically for the management

- Knowledge and insight about sustainable higher education within the organization have increased due to the assessment.

- Enthusiasm and support for working on sustainable higher education within this organization have increased due to the assessment.

- I expect that the assessment will lead to concrete policy developments of the organization.

- Weighing costs and effects, the AISHE assessment was worth the investment.

Assertions were proposed to the participants of the practical tests during the final development phase of AISHE. The participants could react with "agree fully," "agree partially," "disagree partially," or "disagree fully." In addition, they had the opportunity to add comments for each answer. Above are examples of the assertions. 
This article has been cited by:

1. Anirban Chakraborty, Sumit Kumar, L. S. Shashidhara, Anjali Taneja. 2021. Building Sustainable Societies through PurposeDriven Universities: A Case Study from Ashoka University (India). Sustainability 13:13, 7423. [Crossref]

2. Ola Leifler, Jon-Erik Dahlin. 2020. Curriculum integration of sustainability in engineering education - a national study of programme director perspectives. International Journal of Sustainability in Higher Education 21:5, 877-894. [Crossref]

3. Nathália Hipólito Cardozo, Sérgio Ricardo da Silveira Barros, Osvaldo Luis Gonçalves Quelhas, Euricerio Rodrigues Martins Filho, Wagner Salles. Benchmarks Analysis of the Higher Education Institutions Participants of the GreenMetric World University Ranking 667-683. [Crossref]

4. Naomi M. Maina-Okori. Sustainability Domains in Higher Education 1653-1661. [Crossref]

5. Naomi M. Maina-Okori. Sustainability Domains in Higher Education 1-9. [Crossref]

6. David Alba-Hidalgo, Javier Benayas del Álamo, José Gutiérrez-Pérez. 2018. Towards a Definition of Environmental Sustainability Evaluation in Higher Education. Higher Education Policy 31:4, 447-470. [Crossref]

7. Katrien Van Poeck, Ariane König, Arjen E. J. Wals. 2018. Environmental and sustainability education in the Benelux countries: research, policy and practices at the intersection of education and societal transformation. Environmental Education Research 24:9, 1234-1249. [Crossref]

8. Idoya Ferrero-Ferrero, María Ángeles Fernández-Izquierdo, María Jesús Muñoz-Torres, Lucía Bellés-Colomer. 2018. Stakeholder engagement in sustainability reporting in higher education. International Journal of Sustainability in Higher Education 19:2, 313-336. [Crossref]

9. Meeri Karvinen, Ullika Lundgren, Helena Mälkki, Jaana Sorvari. The Implementation of Sustainable Development in the Nordic Higher Education Institutions (HEIs) 169-187. [Crossref]

10. Graham Bullock, Nicholas Wilder. 2016. The comprehensiveness of competing higher education sustainability assessments. International Journal of Sustainability in Higher Education 17:3, 282-304. [Crossref]

11. Heloisa Cronemberger de Araújo Góes, Alessandra Magrini. 2016. Higher education institution sustainability assessment tools. International Journal of Sustainability in Higher Education 17:3, 322-341. [Crossref]

12. Tove Holm, Kaisu Sammalisto, Thomas S. Grindsted, Timo Vuorisalo. 2015. Process framework for identifying sustainability aspects in university curricula and integrating education for sustainable development. Journal of Cleaner Production 106, 164-174. [Crossref]

13. Wim Lambrechts. 2015. The contribution of sustainability assessment to policy development in higher education. Assessment \& Evaluation in Higher Education 40:6, 801-816. [Crossref]

14. Aisling Tierney, Hannah Tweddell, Chris Willmore. 2015. Measuring education for sustainable development. International Journal of Sustainability in Higher Education 16:4, 507-522. [Crossref]

15. Slobodan Milutinović, Vesna Nikolić. 2014. Rethinking higher education for sustainable development in Serbia: an assessment of Copernicus charter principles in current higher education practices. Journal of Cleaner Production 62, 107-113. [Crossref]

16. Raine Isaksson, Mikael Johnson. 2013. A Preliminary Model for Assessing University Sustainability from the Student Perspective. Sustainability 5:9, 3690-3701. [Crossref]

17. Philip Vaughter, Tarah Wright, Marcia McKenzie, Lauri Lidstone. 2013. Greening the Ivory Tower: A Review of Educational Research on Sustainability in Post-Secondary Education. Sustainability 5:5, 2252-2271. [Crossref]

18. Niko Roorda. A Strategy and a Toolkit to Realize System Integration of Sustainable Development (SISD) 101-119. [Crossref]

19. Ana C Madeira, Maria Antónia Carravilla, José F Oliveira, Carlos A V Costa. 2011. A Methodology for Sustainability Evaluation and Reporting in Higher Education Institutions. Higher Education Policy 24:4, 459-479. [Crossref]

20. Pim Martens, Niko Roorda, Ron Cörvers. 2010. The Need for New Paradigms. Sustainability: The Journal of Record 3:5, 294-303. [Abstract] [PDF] [PDF Plus]

21. Shirley Vincent, Will Focht. 2010. Environmental Reviews and Case Studies: In Search of Common Ground: Exploring Identity and Core Competencies for Interdisciplinary Environmental Programs. Environmental Practice 12:1, 76-86. [Crossref] 